Revista Água Viva

ISSN 1678-7471

\title{
LÍNGUAS DE HERANÇA E DE IMIGRAÇÃO: NOTAS SOBRE COMUNIDADES LINGUÍSTICAS E (CO) EXISTÊNCIA SOCIOCULTURAL NO BRASIL
}

\author{
HERITAGE AND IMMIGRATION LANGUAGES: NOTES ON LANGUAGE \\ COMMUNITIES AND (CO) SOCIOCULTURAL EXISTENCE IN BRAZIL
}

\author{
Isabela Vieira Barbosa ${ }^{1}$ \\ Caique Fernando da Silva Fistarol ${ }^{2}$ \\ Éderson Luís Silveira ${ }^{3}$
}

Recebido em: 30 mar. 2020

Aceito em: 29 nov. 2020

DOI: 10.26512/aguaviva.v5i3.35812

RESUMO: Neste artigo serão apresentados dados referentes a algumas línguas de (descendentes de) imigrantes que hoje estão no Brasil. Discute-se, ainda, o quão importante foi a vinda dos imigrantes para o pluralismo sociocultural nacional. Conclui-se que as línguas de imigração e de herança são patrimônios socioculturais, pois marcaram e ainda marcam a história linguística e cultural do Brasil. Cabe salientar que, aqui, o termo língua de herança está sendo usado para denominar as línguas dos descendentes que já nasceram no Brasil enquanto que o termo língua de imigração estaria mais relacionado à língua da primeira geração, ou seja, a dos imigrantes de fato. Esta herança fixada ao longo dos anos trouxe à população uma ampliação no âmbito da diversidade linguística já existente, cujos efeitos perduram nos dias de hoje.

Palavras-chave: Línguas de imigração e de herança. Concepções de bilinguismo. Educação bilíngue.

ABSTRACT: In this paper will be presented data referring to some languages of (descendants of) immigrants who are currently in Brazil. It also discusses how important the coming of immigrants to national sociocultural pluralism was. It is concluded that the languages of immigration and heritage are sociocultural heritages, as they marked and still mark the linguistic and cultural history of Brazil. It should be noted that, here, the term inheritance language is being used to name the languages of descendants who were born in Brazil while the term

\footnotetext{
${ }^{1}$ Mestra em Educação pela Universidade Regional de Blumenau (FURB); Possui Pós-Graduação em Educação Infantil e Desenvolvimento pela Universidade Cândido Mendes e especialização em Gestão Educacional pela UNIASSELVI. E-mail: miss.vieira@gmail.com

${ }^{2}$ Mestre em Educação pela Universidade Regional de Blumenau (FURB). Professor de Língua Inglesa na Rede Municipal de Ensino de Blumenau/SC. Atualmente, atua como Coordenador do Ensino Bilíngue e de Língua Inglesa da Rede Municipal de Ensino de Blumenau/ SC. E-mail: cfersf@gmail.com

3 Doutor e Mestre em Linguística pela Universidade Federal de Santa Catarina (UFSC). E-mail: ediliteratus@gmail.com
} 
immigration language would be more related to the language of the first generation, that is, that of immigrants in fact. This heritage fixed over the years has brought to the population an expansion in the context of existing linguistic diversity, the effects of which persist today.

Keywords: Languages of immigration. Conceptions of bilingualism. Bilingual education.

\section{INTRODUZINDO O PERCURSO}

As línguas de imigração e de herança são patrimônios socioculturais, pois marcaram e ainda marcam a história linguística e cultural do Brasil. De acordo com Bolognini e Payer (2005, p. 43) “[...] o português nem sempre foi a língua mais falada no Brasil. Houve um período no qual a língua mais falada no Brasil era a língua geral, e foi apenas a partir dos séculos XVII e XVIII que essa língua perdeu espaço para o português, devido à obrigatoriedade do seu uso e do seu ensino". Sobre a língua geral pode ser mencionado que, de acordo com a Enciclopédia das Línguas no Brasil (2020), do Laboratório de Estudos Urbanos da Unicamp, trata-se do resultado de um aglomerado de línguas de base indígena praticadas em território de domínio português durante o período de colonização do Brasil. Nesse sentido, os autores mencionam que as línguas de matriz indígena, até então, miscigenavam-se dentro do território brasileiro, mas que, com a vinda dos portugueses ao Brasil e com as questões socioculturais associadas, houve uma imposição da língua portuguesa como língua nacional, o que fez com que esta última se tornasse, assim, a língua mais falada no país.

O bilinguismo ${ }^{4}$ é concebido como a capacidade do ser humano em comunicar-se por meio de duas línguas, na maior parte das vezes, a materna e outra estrangeira. Assim, Barker e Prys (1998), Li Wei (2000) argumentam que o termo bilíngue basicamente pode definir indivíduos que possuem duas línguas. Nesse contexto, é importante mencionar que os imigrantes não raras vezes dominavam duas línguas e, inclusive, variedades diferentes da mesma língua, podendo ser considerados bilíngues já no contexto de origem. Entretanto, mesmo havendo maior concentração de imigrantes em algumas localidades que de brasileiros falantes de língua portuguesa, manteve-se a sobreposição da língua portuguesa - exceto na privacidade do espaço familiar onde, em diversas localidades de fala alemã, predominava o alemão - e também de um efeito valorativo hierarquizador da cultura dela adjacente sobre a estrangeira. Porém, é

\footnotetext{
${ }^{4}$ Para obter mais informações acerca da dificuldade em distinguir e conceptualizar detalhadamente o conceito de bilinguismo, sugere-se que seja consultado o texto de Megale (2005).
} 
necessário ressaltar que os brasileiros absorveram costumes dos imigrantes, como a culinária, vestimentas e rituais religiosos, que passaram a fazer parte da herança cultural de muitos brasileiros.

Neste cerne, este artigo visa assinalar que a diversidade linguística foi fundamental para constituir a história do Brasil. Os dados do presente artigo, neste sentido, são um recorte de uma pesquisa maior realizada sobre o bilinguismo e o ensino bilíngue no Brasil. Entretanto, optouse por realizar neste artigo, um recorte apenas sobre as línguas de imigração e de herança.

\section{Contextos de imigração}

O processo imigratório brasileiro foi composto por diferentes momentos históricos e políticos que contribuíram para a imigração voluntária ${ }^{5}$ de diferentes grupos sociais. Em uma sociedade composta de forma tão plural e singular, ao esmiuçar as línguas de imigração e, consequentemente, as línguas de herança, encontra-se grande diversidade cultural e singularidades expressas por grupos minoritários aqui apresentados. Para a realização do presente artigo, foram consultadas diferentes bases de dados produções científicas relacionadas às áreas de Educação e de Linguagem, que abordam, em suas pesquisas, concepções de bilinguismo e de educação bilíngue. Entre as teses, dissertações e artigos que compõem o acervo de obras consideradas para o presente trabalho, houve um recorte temporal, a partir do qual foram selecionados apenas artigos, teses e dissertações publicados entre os anos de 2010 e 2019.

As bases de dados pré-selecionadas foram a Biblioteca Digital Brasileira de Teses e Dissertações (BDTD), a Biblioteca Digital da Universidade Regional de Blumenau (FURB) e da Universidade de São Paulo (USP). A seleção das duas últimas se deu em virtude do conhecimento de pesquisas realizadas no Programa de Mestrado em Educação das instituições com línguas de imigração. Após o levantamento nas bases de dados, a procura por pesquisas relacionadas às áreas de Educação e de Linguagem, com foco em bilinguismo e educação bilíngue, chegou-se a 81 documentos que atendiam aos critérios preestabelecidos. Entretanto,

\footnotetext{
${ }^{5}$ Neste recorte, abordaremos apenas as imigrações voluntárias europeias estimuladas por crises financeiras e sociais na Europa, ou por acordos internacionais estabelecidos. As imigrações forçadas como as ocorridas no continente Africano foram parte do projeto maior, mas não farão parte deste recorte.
} 
ainda foi necessária uma análise textual dos trabalhos para compreender quais possuíam proximidade com o tema.

Os 81 documentos selecionados compõem o corpus da pesquisa maior, na qual este artigo está inserido. Para o presente trabalho foi realizado um recorte apenas das pesquisas que apresentavam as línguas de imigração, correspondendo, portanto, a um total de 46 trabalhos. Segundo o Quadro 1, pode-se notar que nas pesquisas encontradas nos defrontamos com 14 línguas de origens alóctones: sendo três de origem asiática e outras onze de procedência europeia.

Quadro 1 - Incidência de línguas de imigração encontradas

\begin{tabular}{|l|c|}
\hline \multicolumn{1}{|c|}{ Língua de imigração } & Incidência \\
\hline Alemão & 13 \\
\hline Árabe & 01 \\
\hline Chinês & 01 \\
\hline Coreano & 01 \\
\hline Espanhol & 01 \\
\hline Francês & 04 \\
\hline Holandês & 01 \\
\hline Hunsrückisch & 05 \\
\hline Inglês & 02 \\
\hline Italiano & 10 \\
\hline Japonês & 03 \\
\hline Pomerano & 02 \\
\hline Ucraniano & 01 \\
\hline Westfaliano & \\
\hline
\end{tabular}

Fonte: Elaborado pelos autores 
Sobre o contato linguístico pode ser afirmado que: “[o] contato linguístico entre língua majoritária oficial e língua minoritária familiar/comunitária pode desenvolver fenômenos muito especiais e peculiares do ponto de vista linguístico [...]” (SPINASSÉ, 2008, p. 118). Esse contato entre os imigrantes alemães e suas línguas faladas na época da imigração com o português gerou diferentes fenômenos linguísticos bem como resultou em línguas teutobrasileiras.

Assim como hoje, no século XIX os falantes de alemão se comunicavam por meio de variedades dessa língua. Vale considerar que até 1870 nao existia Alemanha. O que havia eram imigrantes de fala alemã emigrados de regiões diversas da Áustria, da Prússia, dos Países Baixos, etc. Assim, é importante mencionar que os imigrantes que adentraram o Brasil, a partir de 1824, falavam variedades distintas do alemão e do baixo-alemão. Na época a justificativa era de que, uma vez que estes estavam divididos em estados não unificados, nem todos falavam o mesmo "alemão". Hoje essas variedades do alemão continuam a existir - porém não com as mesmas características - em virtude dos fatores sócio-históricos que ainda exercem influências nos sujeitos descendentes que no Brasil residem.

Compreende-se hoje, também, que, ao iniciar o processo imigratório, os grupos de origem alemã não vinham das mesmas regiões - Boêmia, Westfália, Pomerânia-, representando justamente essa separação cultural do estado alemão à época, e cada grupo trouxe consigo os seus modos de falar e agir. Ao chegarem ao Brasil, diferentes grupos sociais começaram a se encontrar, entretanto, o imigrante novo, recém-chegado, se adaptava e aprendia, com aquele que já estava ali, palavras novas para denominar coisas que nao existiam na sua terra. Spinassé (2008, p. 128) destaca que "[a] maioria dos imigrantes vinha da região mais pobre da Alemanha naquela época, a região do Hunsrück, e sua língua materna era o dialeto ${ }^{1}$ francônio-renano". Spinassé (2008) ressalta ainda que o uso da língua pela maioria contribuiu para a variação linguística e a mudança nas antigas línguas.

Spinassé destaca que “[...] as colônias eram muito semelhantes a 'ilhas' ${ }^{6}$. Essa realidade contribuiu para que as variedades linguísticas alemãs se desenvolvessem de maneira forte e se

\footnotetext{
${ }^{1}$ Apesar de a autora optar pelo termo "dialeto" para se referir às variedades linguísticas de origem alemã, neste trabalho consideram-se as diferentes variedades do alemão como línguas de imigração e de herança, por se entender que o termo "dialeto" está muitas vezes relacionado à desvalorização e hierarquização de línguas, conforme Grosjean (2000).

${ }^{6}$ É importante mencionar que hoje essas comunidades dificilmente podem ser denominadas de ilhas, uma vez que o contato com o português, bem como outras variedades do alemão e com outras línguas, é facilitado pelas mídias, pelas migrações diárias, pela escola, etc.
} 
mantivessem presentes nas comunidades" (SPINASSÉ, 2008, p. 128). Mesmo com as proibições do uso da língua alemã no Brasil durante a Segunda Guerra Mundial ${ }^{7}$, o alemão continuou a ser utilizado nas colônias, bem como continuou a ser passado às novas gerações, mantendo viva a língua de herança, mas também o transformando pela influência do português. Assim, o alemão utilizado pelos imigrantes e seus descendentes se distanciava do considerado alemão standard, tornando-se línguas independentes.

Essa relação de influências entre a língua alemã, o alemão standard e o português proporcionaram mudanças na língua. Spinassé (2008) destaca que, de acordo com a base linguística de maior influência à época, a variedade recebe hoje seu nome baseada na região originária dos imigrantes que a falavam. Por isso, hoje podem ser encontradas variedades como o Pommerisch $^{3}$ (pomerano), o Westfällisch (westfaliano) e o próprio Hunsrückisch (francôniorenano) que se apresenta no Quadro 2 a seguir. Ressalta-se, antecipadamente, que, ao utilizar a expressão alemão standard, não se está comparando-o com as diferentes vertentes da língua, nem elevando tal variação a um grau superior. Apenas está sendo utilizada para definir os trabalhos sobre a língua alemã, nos quais não foram especificados a que variedades pertencem ou que se aproximam do alemão também conhecido como Hochdeutsch.

Quadro 2 - Línguas de origem alemã

\begin{tabular}{|l|c|}
\hline \multicolumn{1}{|c|}{ Línguas de origem alemã } & Incidência \\
\hline Alemão-padrão ou não especificado & 13 \\
\hline Hunsrückisch & 06 \\
\hline Pomerano & 02 \\
\hline Westfaliano & 01 \\
\hline
\end{tabular}

Fonte: Elaborado pelos autores

\footnotetext{
${ }^{2}$ Durante a campanha de nacionalização imposta pelo Estado Novo do presidente Getúlio Vargas, algumas medidas de repressão foram tomadas com o intuito de diminuir a influência dos imigrantes e estrangeiros no Brasil. Entre as medidas estava a proibição de utilizar as línguas de imigração, entendidas como línguas estrangeiras (SEYFERTH, 1997).

${ }^{3}$ Destaca-se aqui que se optou pelo uso de itálico na nomenclatura das diferentes línguas, uma vez que, muitas vezes os nomes das línguas são originários da região ou de um grupo social especifico de mesmo nome, tornando difícil a compreensão dessa separação entre grupos sociais e línguas.
} 
Por meio da leitura do Quadro 2, verifica-se que a maior parte das pesquisas se ateve ao alemão-padrão - standard -, ou simplesmente estas pesquisas optaram em não definir a variação linguística do alemão que fora pesquisada. Entretanto, nota-se também que seis trabalhos abordaram o Hunsrückisch para a pesquisa; duas pesquisas utilizaram o Pomerano e apenas uma o Westfaliano.

Dessa forma, compreende-se, em relação às diferenciações entre tais línguas, que, conforme supracitado, possuem a mesma origem, alemã, mas que, devido a localizações geográficas e contatos linguísticos distintos, se configuraram de formas variadas. Vale destacar que o pomerano e o vestfaliano vêm do baixo-alemão. O Hunsrückisch vem do alto-alemão. Na mesma perspectiva, percebe-se, com a apresentação do Quadro 3, que o contexto sóciohistórico onde as pesquisas foram realizadas possui relação com o processo imigratório e com os grupos de pesquisa já estabelecidos.

Quadro 3 - Contexto sócio-histórico das pesquisas de variedades de herança do alemão

\begin{tabular}{|l|c|c|c|c|}
\hline \multicolumn{1}{|c|}{ Autor } & Língua & Ano & $\begin{array}{c}\text { Tipo de } \\
\text { trabalho }\end{array}$ & $\begin{array}{c}\text { Local } \\
\text { investigado }\end{array}$ \\
\hline BILLIG & Hunsrückisch & 2014 & Tese & $\begin{array}{c}\text { Arroio do } \\
\text { Tigre/RS }\end{array}$ \\
\hline BORELLA & Hunsrückisch & 2014 & Tese & $\begin{array}{c}19 \text { cidades do } \\
\text { Rio Grande do } \\
\text { Sul }\end{array}$ \\
\hline BORGES & Alemão & 2015 & Dissertação & Porto Alegre/RS \\
\hline BREDEMEIER & Alemão & 2010 & Tese & $\begin{array}{c}\text { Revisão } \\
\text { bibliográfica }\end{array}$ \\
\hline BRENTANO & Hunsrückisch & 2011 & Dissertação & e Picada Café/RS \\
\hline BROCH & Alemão & 2014 & Tese & Porto Alegre/RS \\
\hline
\end{tabular}




\begin{tabular}{|c|c|c|c|c|}
\hline DUCK & Alemão & 2011 & Tese & $\begin{array}{c}\text { Colônia } \\
\text { Nova/RS; } \\
\text { Curitiba/PR; } \\
\text { Witmarsum/PR; } \\
\text { Rio Verde/GO }\end{array}$ \\
\hline EWALD & Alemão & 2014 & Dissertação & $\begin{array}{c}\text { Médio Vale do } \\
\text { Itajaí/SC }\end{array}$ \\
\hline GOMES & Alemão & 2014 & Dissertação & $\begin{array}{c}\text { Revisão } \\
\text { bibliográfica }\end{array}$ \\
\hline HORST & Westfaliano & 2014 & Dissertação & $\begin{array}{c}\text { Vale do } \\
\text { Taquari/RS }\end{array}$ \\
\hline KAFER & Hunsrückisch & 2013 & Dissertação & $\begin{array}{c}\text { Nova Petrópolis } \\
\text { e Morro } \\
\text { Reuter/RS }\end{array}$ \\
\hline KISS & Alemão & 2013 & Dissertação & Manaus/AM \\
\hline LARA & Alemão & 2013 & Dissertação & Estrela/RS \\
\hline LIMBERGER & Hunsrückisch & 2014 & Dissertação & $\begin{array}{c}\text { São José do } \\
\text { Hortêncio/RS }\end{array}$ \\
\hline MAAS, $\mathrm{M}^{8}$ & Alemão & 2015 & Artigo & Blumenau/SC \\
\hline MAAS, S. & Alemão & 2010 & Dissertação & Pomerode/SC \\
\hline MARTINS & Hunsrückisch & 2013 & Tese & $\begin{array}{c}\text { Novo Hamburgo } \\
\text { e Morro } \\
\text { Reuter/RS }\end{array}$ \\
\hline MROCZINKSI & Alemão & 2015 & Dissertação & Araraquara/SP \\
\hline MUJICA & Pomerano & 2013 & Dissertação & $\begin{array}{c}\text { São Lourenço do } \\
\text { Sul/RS }\end{array}$ \\
\hline ROSA & Alemão & 2011 & Dissertação & Missal/PR \\
\hline
\end{tabular}

\footnotetext{
${ }^{8}$ Optamos nesta pesquisa em apresentar os sujeitos com sobrenomes semelhantes também com a abreviação do primeiro nome, com o intuito de reforçar a diferenciação entre os pesquisadores e evitar que o leitor confunda suas obras.
} 


\begin{tabular}{|l|c|c|c|c|}
\hline SILLER & Pomerano & 2011 & Tese & $\begin{array}{c}\text { Santa Maria de } \\
\text { Jetibá/ES }\end{array}$ \\
\hline SILVA & Alemão & 2015 & Dissertação & $\begin{array}{c}\text { Arroio do } \\
\text { Padre/RS }\end{array}$ \\
\hline SPIESS & Alemão & 2014 & Dissertação & Pomerode/SC \\
\hline
\end{tabular}

Fonte: Elaborado pelos autores

Borges (2015), Broch (2014), Lara (2013) e Silva (2015) realizaram suas pesquisas sobre alemão na mesma região, o estado do Rio Grande do Sul. Algumas pesquisas como Borges (2015) e Broch (2014) concentraram-se na cidade de Porto Alegre, enquanto Lara (2013) e Silva (2015) se inseriram na região do Vale do Taquari, conhecida pela forte imigração alemã, bem como italiana e açoriana. Vale destacar que Silva (2015) desenvolveu sua pesquisa na Universidade Federal de Pelotas enquanto que Borges (2015), Broch (2014) e Lara (2013) desenvolveram seus estudos na Universidade Federal do Rio Grande do Sul, todos no PPG em Letras da mesma instituição.

Ewald (2014), M. Maas (2015), S. Maas (2010) e Spiess (2014) realizaram suas pesquisas também sobre o alemão em um contexto de imigração, a região do Vale do Itajaí, em Santa Catarina. Além da relação estabelecida entre o contexto histórico de imigração, as pesquisas de Ewald (2014), M. Maas (2015), S. Maas (2010) e Spiess (2014) ainda estão relacionadas pelo contexto de produção, uma vez que as pesquisas foram desenvolvidas na mesma instituição, Universidade Regional de Blumenau (FURB), demonstrando a atuação do grupo de pesquisa.

Neste sentido, podemos observar que as pesquisas sobre línguas de origem alemã conduzidas pelas pesquisadoras (EWALD, 2014; MAAS, 2015; MAAS, 2010; SPIESS, 2014) são reflexo da proximidade sócio-histórica da instituição na qual estavam inseridas, tal como os pesquisadores previamente apresentados que, em virtude da proximidade cultural com as variedades alemãs no Rio Grande do Sul, se situam geograficamente próxima de uma região de imigração alemã e a maioria também executou a pesquisa a partir de uma instituição em comum. Essas proximidades geográficas e sócio-históricas são apresentadas na região historicamente ligada às imigrações alemã e italiana. Pode ser mencionado, também, que Bredemeier (2010) e Gomes (2014), por outro lado, utilizaram levantamentos bibliográficos para investigar o 
português como segunda língua nas escolas de imigração alemã (BREDEMEIER, 2010) e a importância do aprendizado de uma segunda língua (GOMES, 2014).

Todas as pesquisas relacionadas ao Hunsrückisch foram realizadas no estado do Rio Grande do Sul, em regiões em que o alemão ainda se faz presente ${ }^{9}$ (ALTENHOFEN et al., 2007). Ademais, duas pesquisas foram desenvolvidas na Pontifícia Universidade Católica do Rio Grande do Sul (PUCRS) (LIMBERGER, 2014; MARTINS, 2013), por diferentes orientadores que atuam junto no grupo de pesquisa "Núcleo de Estudos em Leitura- NEL" 4". As demais pesquisas (BILLIG, 2014; BORELLA, 2014; BRENTANO, 2011; KAFER, 2013) também realizadas no estado do Rio Grande do Sul, novamente se relacionam não apenas pela região na qual a pesquisa foi desenvolvida, mas pela conexão com os grupos de pesquisa e orientadores. Realizadas na Universidade Federal do Rio Grande do Sul (UFRGS), as pesquisas de Borella (2014) e Kafer (2013) ainda se vinculam ao grupo "Alma Linguae: Variação e Contatos de Línguas Minoritárias", reforçando a relação estabelecida entre grupos de pesquisa, instituições e as produções acadêmicas sobre as línguas de imigração. O Hunsrückisch não é apenas uma das línguas minoritárias a ser mencionada. Ocupa um lugar de destaque porque é uma das línguas da diversidade linguística que melhor está documentada no Brasil, como mencionam Altenhofen e Morello (2018, p. 17). Os autores mencionam que hoje a língua mencionada representa um conceito de alcance internacional e que tem a melhor documentação de todas devido à existência do Inventário do Hunsrückisch como Língua Brasileira de Imigração (IHLBrI).

Outra língua que pode ser mencionada é o pomerano ou pomerisch, que é uma língua alemã de origem na região da Pomerânia, hoje pouco utilizada e conhecida na Alemanha, mas bastante viva no Brasil. De acordo com Tressmann (apud EUCLYDES, 2014), o pomerano foi considerado uma língua oficial até o ano de 1600, sendo bastante usada no comércio durante a Idade Média. Até hoje, a palavra Pomerânia se refere à região nordeste alemã e noroeste polonesa. Entretanto, ao contrário do que muitos entendem, o pomerano não é um dialeto

\footnotetext{
${ }^{9}$ Vale destacar, neste contexto, que o professor Dr. Cléo Vilson Altenhofen - da UFRGS-, juntamente a professora Dra. Rosângela Morello - do IPOL -, coordenam a Equipe de Execução do Inventário do Hunsrückisch como Língua Brasileira de Imigração (IHLBrI) - ela é responsável pela coordenação Geral e ele a Coordenação de Pesquisas de Campo. O professor também coordena, na UFRGS, juntamente com o professor Harald Thun - da Universidade Kiel, da Alemanha - o Projeto ALMA-H (Atlas Linguístico-Contatual das Minorias Alemãs na Bacia do Prata: Hunsrückisch).

${ }^{4} \mathrm{O}$ "Núcleo de Estudos em Leitura - NEL" é um grupo de pesquisa vinculado a UFSC liderado pela Profa. Dra. Leda Maria Braga Tomitch, que apresenta como objetivo principal desenvolver pesquisas na área de processamento e compreensão da linguagem escrita, incluindo tanto os aspectos cognitivos como os instrucionais.
} 
alemão. Tressmann (apud EUCLYDES, 2014, s. p.) destaca que o pomerano e o alemão standard, "são duas línguas que nasceram de modo diferente. A ancestralidade da língua pomerana tem a ver com o holandês, com o westfaliano e até com o saxão antigo".

A primeira língua de herança do Brasil a ser co-oficializada, o pomerano, encontra-se ainda presente em seis cidades que a possuem como língua oficial. São elas: Santa Maria de Jetibá, Domingos Martins, Pancas, Vila Pavão e Laranja da Terra, no estado do Espírito Santo, e Canguçu, no Rio Grande do Sul (EUCLYDES, 2014). Neste contexto, vale destacar que Siller (2011) inseriu-se justamente na cidade de Santa Maria de Jetibá/ES para investigar a língua enquanto que Mujica (2013) optou pela cidade de São Lourenço do Sul/RS, vizinha da cidade de Canguçu/RS que a possui como língua oficial do município.

Quadro 4 - Contexto sócio-histórico das demais pesquisas de línguas de herança de origem europeia

\begin{tabular}{|c|c|c|c|c|}
\hline Autor & Língua & Ano & $\begin{array}{l}\text { Tipo de } \\
\text { trabalho }\end{array}$ & Local investigado \\
\hline AZEREDO & Italiano & 2012 & Dissertação & Flores da Cunha/RS \\
\hline $\mathrm{BROCH}$ & Francês & 2014 & Tese & Porto Alegre/RS \\
\hline BULLIO & Francês & 2014 & Tese & Porto Alegre/RS \\
\hline FERRARI & Italiano & 2010 & Dissertação & $\begin{array}{c}\text { Belo Horizonte/MG e } \\
\text { São Paulo/SP }\end{array}$ \\
\hline FERRONI & Italiano & 2012 & Tese & São Paulo/SP \\
\hline KISS & Francês & 2013 & Dissertação & Manaus/AM \\
\hline KRIESER & Italiano & 2015 & Dissertação & Rodeio/SC \\
\hline KUYUMJIAN & Francês & 2014 & Dissertação & Não definido \\
\hline LEOPOLDINO & Italiano & 2014 & Tese & Piracicaba/SP \\
\hline LORENZI & Italiano & 2014 & Dissertação & Rodeio/SC \\
\hline \multirow[t]{2}{*}{ NOBRE } & Francês & \multirow[t]{2}{*}{2011} & \multirow[t]{2}{*}{ Dissertação } & \multirow[t]{2}{*}{ Revisão bibliográfica } \\
\hline & Holandês & & & \\
\hline
\end{tabular}




\begin{tabular}{|c|c|c|c|c|}
\hline & Italiano & & & \\
\hline PEREIRA, L & Italiano & 2012 & Dissertação & $\begin{array}{c}\text { Nova Pádua e Caxias do } \\
\text { Sul/RS }\end{array}$ \\
\hline PINHEIRO & Italiano & 2014 & Tese & $\begin{array}{c}\text { Nordeste do Rio Grande } \\
\text { do Sul }\end{array}$ \\
\hline QUADROS & Italiano & 2013 & Dissertação & Belo Horizonte/MG \\
\hline SILVA, A. & Francês & 2010 & Dissertação & Goiânia/GO \\
\hline SIMIONATO & Ucraniano & 2012 & Tese & Prudentópolis/PR \\
\hline VIEIRA & Italiano & 2010 & Dissertação & São Paulo/SP \\
\hline
\end{tabular}

Fonte: Elaboração dos autores

No quadro acima, apresentamos de que forma o contexto sócio-histórico das demais pesquisas de línguas de herança se relacionam com o local de investigação. A língua menos citada foi o Westfaliano, assim como as demais línguas de origem alemã, teve um intenso contato com o português e outras variedades linguísticas. A língua tem origem na região que hoje abarca o estado de Nordrhein-Westfalen. Como ressaltado por outros autores anteriormente, os fatores geográficos e socioculturais foram determinantes para a manutenção da língua. Outro fator associado à resistência do Westfaliano é o fato de as línguas francônias, como o Hunsrü̈ckisch, e o alemão standard apresentarem inúmeras características fonológicas e vocabulário diferentes (LUERSEN, 2009). Hoje, tem-se conhecimento de duas ilhas linguísticas que conservam o Westfaliano, estando elas localizadas na região do Vale do Taquari, no Rio Grande do Sul, contexto de pesquisa de Horst (2014), e no sudoeste de Santa Catarina.

Ao longo da história brasileira, o Estado francês tentou por diversas vezes invadir o Brasil ou estabelecer em nosso país colônias francesas. No entanto, as pesquisas aqui relacionadas e apresentadas no Quadro 4, pouco se associam a esse passado de invasões e tentativas. Diante disso, cabe assinalar que Broch (2014), Bullio (2014), Kiss (2013) e A. Silva (2010) apresentam contextos de imigração recentes e específicos, ocorridos nos séculos XX e XXI, e distantes de processos migratórios de massa. Por outro lado, Nobre (2011), ao optar por uma revisão bibliográfica, integra as origens e os contextos de diferentes línguas de imigração, 
abordando o holandês e o francês dentro do contexto de imigração do norte e nordeste brasileiro em virtude das invasões holandesas.

\begin{abstract}
Um aspecto interessante tem a presença dos holandeses no Brasil. Em se tratando da introdução dessa língua no país, há dois períodos que merecem destaque. O primeiro deles remonta ao século XVII, quando houve a tentativa de colonização do país por parte dos holandeses. A importância desse período deve-se ao incentivo cultural propiciado pelo governo holandês estabelecido no Brasil. Como resultado, temos a criação de uma biblioteca, da imprensa e o testemunho da época retratado em quadros e escrito em livros de holandeses. O segundo momento ocorre a partir de meados do século XX, quando houve imigração oficial, com a compra de um grande lote de terras, onde hoje está situada a cidade de Holambra, no interior paulista. O destaque fica marcado, nesse período, pela grande produtividade e contribuição sócio-econômica da comunidade para o Brasil. É nessa região que o holandês ainda é falado no país. Estima-se que entre dez e trinta mil imigrantes falantes de holandês tenham vindo ao Brasil (BOLOGNINI; PAYER, 2005).
\end{abstract}

Já a língua italiana ocupou o foco das pesquisas de Azeredo (2012), L. Pereira (2012), Pinheiro (2014), Krieser (2015), Lorenzi (2014), Ferrari (2010), Quadros (2013), Ferroni (2012), Leopoldino (2014) e Vieira (2010). Vale mencionar que os primeiros imigrantes italianos começaram a chegar ao Brasil na década de 1870. A vinda se deu ora de forma espontânea, ora de modo organizado. É necessário destacar que, na segunda metade do século XIX, houve um dos mais expressivos movimentos migratórios da humanidade. Foi quando 10 milhões de europeus vieram para a América. Os números são expressivos: entre 1875 e 1900 pelo menos 803 mil imigrantes europeus vieram ao continente americano, chegando através de portos brasileiros.

Vale mencionar que, do total de imigrantes europeus que migraram para a América, 577 mil eram italianos. De acordo com informações do Museu da Imigração de São Paulo (2020), a cada 100 imigrantes europeus que vieram para a América no período mencionado, 57 eram italianos e vinham ao Brasil, instalando-se, principalmente, em São Paulo e no Rio Grande do Sul. Sobre o contexto de imigração, pode ser mencionado que a vinda de imigrantes foi espontânea e organizada. A forma espontânea se deu na primeira metade do século XIX quando famílias e indivíduos isoladamente vinham tentar a vida nas cidades brasileiras: padres, arquitetos, músicos, industrialistas, alfaiates e artistas plásticos. Já no caso da imigração organizada, esta se deu de duas formas: 
A imigração organizada de europeu para o Brasil tem duas etapas. Em 1845, foi aprovada uma lei que garantia subvenção governamental para financiar a imigração, visando introduzir nos cafezais o sistema de parceria, introduzindo a mão-de-obra branca livre em paralelo ao trabalho escravo. A segunda fase acompanha o surgimento da Associação Auxiliadora da Colonização e Imigração para a Província de São Paulo, em 1871, e a Sociedade Promotora da Imigração em São Paulo em 1866, que estimulavam a imigração, com subvenção estatal, passagens gratuitas, recepção no porto, acomodação e transporte até as fazendas de cafezais. Os números são impressionantes: ente 1874 e 1889, vieram para o Brasil, ao todo, 320.373 italianos quase a metade para São Paulo. Os imigrantes eram recrutados por agentes a serviço das sociedades promotoras da imigração, os quais vendiam a imagem de um paraíso no Brasil. Os italianos imaginavam que viriam para o "paese dela cucagna" (país da fortuna). A travessia do Atlântico durava de 14 a 30 dias. Superlotação e epidemias nos navios eram constantes. Ao chegarem, permaneciam em quarentena nas hospedarias mantidas pelo governo, de onde tomavam dois rumos distintos: os cafezais paulistas, em substituição ao escravo, ou as colônias do Rio Grande do Sul, em busca do sonho de liberdade e independência (MUSEU ETNOGRÁFICO DA COLÔNIA MACIEL, 2020, s. p.).

Entre as pesquisas mencionadas, pode ser assinalado que Ferrari (2010), Quadros (2013), Ferroni (2012), Leopoldino (2014) e Vieira (2010) destacam a cultura italiana presente nos estados de Minas Gerais e de São Paulo ainda no fim do século XIX. Abordam que a cafeicultura no estado de Minas Gerais foi a principal razão para o estabelecimento de imigrantes italianos que foram utilizados como mão-de-obra no setor agrícola. Entretanto, Botelho, Braga e Andrade (2007) destacam que muitos imigrantes seguiram para o estado de São Paulo em virtude dos subsídios oferecidos (BOTELHO; BRAGA; ANDRADE, 2007). Porém, cabe ressaltar que São Paulo e Minas Gerais não foram os únicos estados a receberem imigrantes italianos. O Rio Grande do Sul também recebeu sua primeira leva de imigrantes, que deram origem às colônias de Conde D'Eu, Dona Isabel e Campo dos Bugres, atualmente Garibaldi, Bento Gonçalves e Caxias do Sul respectivamente (TRENTO, 1989).

Regionalmente, em Pelotas, nas proximidades com Canguçu, foi criado, no início dos anos 2000, o Museu Etnográfico da Colônia Maciel, através de um projeto de pesquisa desenvolvido pelo Laboratório de Ensino e Pesquisa em Antropologia e Arqueologia da Universidade Federal de Pelotas. O projeto busca investigar a trajetória da imigração italiana na região. Visando a preservação da memória dos antepassados, foi inaugurado em 2006. Na 
página oficial do Museu podem ser encontradas informações sobre o início da imigração italiana no estado do Rio Grande do Sul, que remonta ao século XIX (desde meados de 1870):

Entre 1870 e 1872, o governo imperial decide povoar áreas da província de São Pedro do Rio Grande do Sul, com o objetivo de ocupar vazios do território na sua porção mais meridional e de intensificar a produção de alimentos para abastecer as cidades. Escolheram a Serra Gaúcha, em decorrência de sua localização, mais próxima da capital, demarcando em 1874 as colônias de Conde d'Eu (Garibaldi) e Dona Isabel (Bento Gonçalves).

Em 20 de maio de 1875, os primeiros italianos chegaram ao Campo dos Bugres (Caxias do Sul). Inaugurou-se então o primeiro ciclo imigratório, de 1875 a 1914. Instaram-se no Rio Grande do Sul 84 mil italianos vindos, sobretudo da lombardia, Vêneto e Tirol. O ponto culminante da imigração foi entre 1884 e 1894, abrangendo cerca de 60 mil italianos, diminuindo a partir de então com o cancelamento da concessão de passagem transoceânicas pelo governo republicano.

As cinco primeiras colônias imperiais, reconhecidas pela historiografia, foram:

1874 - Colônia Dona Isabel (Bento Gonçalves) e Conde d'Edu (Garibaldi)

1875 - Colônia Fundos de Nova Palmira (Caxias do Sul)

1877 - Silveira Martins (próximo a Santa Maria)

1884 - Colônia Álvaro Chaves (Veranópolis)

1885 São Marcos e Antônio Prado

No entanto, é necessário que a historiografia da imigração reconheça a Colônia Maciel como a quinta colônia imperial, posto que foi criada oficialmente em 1881.

A primeira parada destes imigrantes era o Rio de Janeiro, de onde rumavam para o porto de Rio Grande, seguindo então pela Lagoa dos Patos até Porto Alegre. Permaneciam semanas ou meses em barracões comuns, devendo prestar trabalho compulsório na abertura de estradas. Finalmente, recebiam do governo seu de terra, sementes e ferramentas agrárias (machado, facão curvo, faca, enxada e pá) Trouxeram consigo a cultura do vinho, cuja comercialização lhes permitiu acumular capitais que mais tarde se tornaram pujantes indústrias.

O elemento religioso era o centro da vida dessas comunidades católicas fervorosas. Por meio da religião, os italianos exerceram grande influência sobre a cultura rio-grandense. Padre e freiras tiveram uma intensa participação na instrução religiosa e laica no estado (MUSEU ETNOGRÁFICO DA COLÔNIA MACIEL, 2020, s. p.). 
Vale destacar que, em determinado momento, devido à falta de terras, os imigrantes italianos passaram a se espalhar pelo Rio Grande do Sul, criando colônias no centro e nordeste do estado. Azeredo (2012) inseriu-se no município de Flores da Cunha que, no início do século XX, já era colônia italiana para realizar sua pesquisa. Já Pereira (2012) optou pelo município de Nova Pádua, vizinho da cidade de Flores da Cunha e uma das primeiras colônias, Caxias do Sul. Pinheiro (2014), por outro lado, realizou a pesquisa em 19 diferentes municípios, todos na região nordeste do Rio Grande do Sul onde se encontram cidades como Bento Gonçalves, Garibaldi, Flores da Cunha e Farroupilha.

Santa Catarina recebeu os primeiros imigrantes italianos ainda no início do século XIX, por volta de 1870, oriundos em sua maioria do norte da Itália, dos atuais estados do Vêneto, Lombardia, Friuli-Veneza Júlia e Trentino-Alto Ádige. Contudo, nas primeiras levas imigratórias o baixo número de italianos pouco alterou a cultura da região. Mas, a partir de 1875, as principais levas de imigrantes começaram a estabelecer colônias em Rio dos Cedros, Rodeio, Ascurra e Apiúna, em torno da colônia alemã de Blumenau (TRENTO, 1989). Os trentinos predominavam nas colônias do norte de Santa Catarina, mas, nos anos seguintes, o sul do estado foi foco massivo de criação de diversas colônias, tornando-se o principal foco de colonização do estado. Vale destacar que foi na região do Vale do Itajaí, por exemplo, hoje município de Rodeio, próximo à cidade de Blumenau, que Krieser (2015) e Lorenzi (2014) realizaram suas pesquisas.

A respeito do ingresso dos ucranianos no Brasil, Guérios (2012) destaca que os primeiros grupos de ucranianos que vieram para o Brasil nos anos de 1895 e 1896, se instalaram no estado do Paraná e eram conhecidos como "rutenos", pois “[...] era sob essa denominação que a Igreja Católica Romana e as autoridades do Império Austro-Húngaro referiam-se à população camponesa de religião greco-católica (uniatista) que vivia na Província da Galícia, no extremo leste desse Império" (GUÉRIOS, 2012, p. 11). Guérios (2012) ainda destaca que, em virtude da sobrecarga de imigrantes ucranianos nas primeiras colônias, foram fundadas as demais colônias, entre elas a de Prudentópolis em 1907, onde Simionato (2012) realizou sua pesquisa de doutorado. Para os ucranianos, mudar de país implicou numa ruptura, sendo necessária uma reelaboração social a partir da construção de referenciais identitários no Brasil. Isso porque, ao contrário do que acontecia na Ucrânia, "no Paraná as possibilidades de contato entre colonos eram menores. Eles viviam distantes entre si, não havia reuniões e organizações, 
não havia a presença de senhores e a presença do Estado era pequena" (GUÉRIOS, 2012, p. 128). É aí que a igreja se torna um elemento principal que ajuda a agregar a identidade de um povo em solo estrangeiro, daí as comunidades ucranianas se desenvolverem em torno da construção de um templo religioso, a partir do qual construíam sua morada e se fixavam.

Apesar de aparecerem em maior número, as línguas de herança, oriundas dos processos de transformação das línguas de imigração europeias não são a totalidade do apresentado nessas pesquisas. Línguas de origem árabe e de origem asiática, como o japonês, o coreano e o chinês fazem-se presentes também entre as pesquisas, conforme o quadro a seguir.

Quadro 5 - Contexto sócio-histórico das pesquisas de línguas de imigração de origem asiática

\begin{tabular}{|l|c|c|c|c|}
\hline \multicolumn{1}{|c|}{ Autor } & Língua & Ano & $\begin{array}{c}\text { Tipo de } \\
\text { trabalho }\end{array}$ & Local investigado \\
\hline ABREU & Árabe & 2012 & Tese & Londrina/PR \\
\hline IZAWA & Japonês & 2015 & Dissertação & São Paulo/SP \\
\hline IZUMI & Japonês & 2010 & Dissertação & São Paulo/SP \\
\hline SAKAGUCH & Coreano & 2010 & Dissertação & São Paulo/SP \\
\hline TAKANO & Japonês & 2013 & Tese & Distrito Federal \\
\hline YIN & Chinês & 2013 & Dissertação & São Paulo/SP \\
\hline
\end{tabular}

Fonte: Elaborado pelos autores

Os países asiáticos sempre tiveram movimentos imigratórios consideráveis. A título de exemplo, estima-se que um terço da população asiática no mundo seja composto de imigrantes (BI, 2014). Neste contexto, pode ser mencionado que a imigração japonesa teve como marco inicial a chegada do navio Kasato-Maru em São Paulo no dia 18 de junho de 1908, onde se concentra a maior colônia japonesa no Brasil (MOTOYAMA, 2011). Neste sentido, duas das três pesquisas (IZAWA, 2015; IZUMI, 2010) sobre o japonês foram realizadas na cidade de São Paulo/SP. A pesquisa de Takano (2013) foi realizada em Brasília/DF, entretanto também 
inserida em uma comunidade de imigrantes que chegaram ao Distrito Federal no ano de 1957 (MOTOYAMA, 2011).

As imigrações chinesas e coreanas não possuem uma data oficial de início, porém, sabese que as principais levas de imigrante vieram após o fim da Guerra na Coréia (1950-1953) e da Segunda Guerra Mundial (1939-1945) (MOTOYAMA, 2011). Com o golpe militar ocorrido na Coreia em 1961, muitos sul-coreanos começaram a ver o Brasil como uma possibilidade de destino imigratório. De acordo com Lee (1995), em 1963, chegou ao Porto de Santos a primeira leva de imigrantes coreanos no Brasil.

Sakaguchi (2010) pesquisou na cidade de São Paulo o bilinguismo no contexto de imigração coreana, uma vez que esse estado mantém até hoje a maior parte dos imigrantes coreanos residentes no Brasil. Outrossim, Bi (2014) afirma que apesar de que a "[...] história da imigração para o Brasil tenha completado 200 anos, o grande fluxo da imigração chinesa só começou a partir dos anos 1950 do século passado, especialmente depois de lançar a política de reforma e abertura que abriu a porta da China para estrangeiros” (BI, 2014).

Hoje, estima-se em 150.000 o número de chineses residentes no Brasil, entre os quais a maioria encontra-se no estado de São Paulo, muito em razão das oportunidades econômicas proporcionadas pela região metropolitana da capital paulista (BI, 2014). Por essa razão, Yin (2013) realizou sua pesquisa dentro do contexto imigratório dos chineses de São Paulo, buscando discutir aspectos relacionados à história da imigração.

Assim, como os demais grupos de origem asiática, os árabes iniciaram seu processo de imigração para o Brasil entre o final do século XIX e o início do século XX. Muitos destes imigrantes estabeleceram-se no Rio de Janeiro e São Paulo, mas alguns se estabeleceram também no estado do Paraná, em cidades como Paranaguá e Antonina e, mais tarde, se dirigindo para municípios como Londrina e Foz do Iguaçu (WACHOWICZ, 1967). Abreu (2012) pesquisou o contexto bilíngue da cidade de Londrina onde os árabes se estabeleceram, em sua maioria libaneses, antes mesmo da fundação do município. Em sua maioria, esses imigrantes se estabeleceram no comércio paranaense contribuindo para o crescimento e a expansão dos municípios. Nesse sentido, pode-se relacionar as produções das línguas de imigração aos grupos de pesquisa que se fazem mais presentes nesse âmbito de pesquisa, grupos os quais possuem foco em línguas de herança e em línguas de imigração, como italiano (UFRGS) e alemão (UFRGS; FURB). 
Portanto, fica evidente, na diversidade de contextos e línguas pesquisados, a pluralidade da cultura brasileira, fruto dessa miscigenação histórica envolta em processos imigratórios voluntários, como de portugueses, espanhóis ou italianos. Outros processos influenciados por guerras ou frutos de acordos econômicos e/ou diplomáticos, como nas culturas asiática e libanesa. Dessa forma, compreende-se que o bilinguismo social se faz presente em um grupo social vinculado à comunidade a qual ele representa.

Os dados levantados apontam que as línguas de imigração pesquisadas apresentam diferentes aspectos do processo de chegada destes imigrantes ao Brasil. Algumas destacam o panorama histórico de imigração, por meio de acordos diplomáticos, econômicos ou em busca de uma qualidade de vida melhor. Outras pesquisas apresentam processos imigratórios distantes das grandes massas vindas no século XIX e no século XX, mas, em geral, as pesquisas demonstram a relação entre a pesquisa realizada e a proximidade com o contexto sócio-histórico do povo e da língua pesquisada. Ficou evidente que as principais instituições de onde teses, dissertações e artigos se originaram estão incluídas em zonas de imigração ou próximas às regiões onde esses grupos historicamente se estabeleceram. Também pode ser mencionado que, em parte, se trata de autores descendentes desses grupos de imigração.

\section{CONSIDERAÇÕES FINAIS}

No ano de 2000, o autor e linguista francês Calvet escreveu brevemente na revista da UNESCO, no seu artigo intitulado "O futuro das línguas" suscitando que a língua só é perpetuada na história por meios dos seus falantes e não exclusivamente pela imposição de políticas públicas de ensino de determinada língua oficial. Isto é, o modo como Calvet (2000) e Silva (2017), reverberando o primeiro, instigam o leitor sobre sua brilhante colocação é fazêlo refletir que o próprio imigrante pode assegurar que sua língua seja mantida, bem como propagá-la dentro de tantas outras culturas.

É preciso desmistificar imaginários culturais reproduzidos socialmente que disseminam preconceitos em relação a imigrantes, o que também acontece em outros países que são resistentes aos imigrantes brasileiros, como no caso de Portugal, onde, em 2019, as denúncias 
de xenofobia contra brasileiros e brasileiras cresceram $150 \%$ em um ano ${ }^{10}$, mas também ocorre por falta de informação e que, na verdade, o direito de ir e vir existe, principalmente quando é oportunizado por meio de qualificação profissional e habilidades, as quais estão escassas em determinadas localidades. Infelizmente, além do direito de ir e vir jazem preconceitos, marginalizações e subalternizações diversas que precisam ser combatidas e problematizadas a fim de gerar criticidade e respeito pela alteridade.

Não serão as políticas que garantirão a continuidade de uma língua, mas o povo que por meio dela se comunica. Logo, as políticas de ensino bilíngue podem contribuir para a disseminação da língua e a propagação desta entre os falantes e o público que terá a possibilidade de aprender esta nova cultura. Assim, o foco de estudar as línguas de imigração e de herança, em pleno século XXI, consiste em compreender que a formação dos usos da língua portuguesa sofreu efeitos de várias outras línguas e que está impregnada em nossa história e cultura. Neste contexto, principalmente, os sujeitos são partes de um todo, que se chama plurilinguismo, mesmo que nem todos busquem se beneficiar dessa fonte rica de conhecimento.

\section{REFERÊNCIAS}

ABREU, M. Y. Interferências no Português falado por imigrantes libaneses em situação de contatos linguístico-culturais em Londrina. 2012. 255 f. Tese (Doutorado em Estudos da Linguagem) - Instituto de Letras e Linguística, Universidade Estadual de Londrina, Londrina, 2012.

ALTENHOFEN, C. V. et al. Fundamentos para uma escrita do Hunsrückisch falado no Brasil. Contingentia, v. 2, p. 73-87, nov. 2007.

ALTENHOFEN, C. V.; MORELlO, R. (Orgs.). Hunsrückisch: inventário de uma língua do Brasil. Florianópolis: Garapuvu, 2018.

AZEREDO, P. S. A troca da vibrante por tepe em onset silábico: Uma análise de variação e mudança linguística na comunidade bilíngue de Flores da Cunha (RS). 2012. 91 f. Dissertação (Mestrado em Letras) - Instituto de Letras, Universidade Federal do Rio Grande do Sul, Porto Alegre, 2012.

BAKER, C.; PRYS J. Encyclopedia of Bilingualism and Bilingual Education. Multilingual Matters, 1998.

BI, M. Y. Imigração chinesa em São Paulo e o seu português falado. Domínios de Lingu@gem, v. 8, n. 3, p. 166-187, 2014.

BILLIG, J. D. Impacto do bilinguismo nas redes de atenção, no acesso lexical e na memória de trabalho em adultos e idosos. 2014. 165 f. Tese (Doutorado em Letras) - Instituto de Letras, Universidade Federal do Rio Grande do Sul, Porto Alegre, 2014.

\footnotetext{
${ }^{10}$ Disponível em: < https://www1.folha.uol.com.br/mundo/2019/05/queixas-de-discriminacao-contra-brasileirosem-portugal-disparam-em-2018.shtml> acessado em 21 out. 2020.
} 
BOLOGNINI, C. Z.; PAYER, M. O. Línguas de imigrantes. Ciência e Cultura, v. 57, n. 2, p. 42-46, abr./jun. 2005.

BORELLA, S. G. "Tu dampém fala assim?" Macroanálises pluridimensionais da variação de sonorização e dessonorização das oclusivas do português de falantes bilíngues do HunsriqueanoPortuguês. 2014. 204 f. Tese (Doutorado em Letras) - Instituto de Letras, Universidade Federal do Rio Grande do Sul, Porto Alegre, 2014.

BORGES, C. L. Panorama do ensino de língua alemã para alunos da educação infantil na região metropolitana de Porto Alegre. 2015. 122 f. Dissertação (Mestrado em Letras) - Instituto de Letras, Universidade Federal do Rio Grande do Sul, Porto Alegre, 2015.

BOTELHO, T. R; BRAGA, M. P; DE ANDRADE, C. V. - Imigração e família em Minas Gerais no final do século XIXI. Revista Brasileira de História, v. 27, n. 54, p. 155-176, 2007.

BREDEMEIER, M. L. L. O português como segunda língua nas escolas da imigração alemã: Um estudo do jornal da associação de professores teuto-brasileiros católicos do Rio Grande do Sul (19001939). 2010. 242 f. Tese (Doutorado em Educação) - Escola de Humanidades, Universidade do Vale do Rio dos Sinos, São Leopoldo, 2010.

BROCH, I. K. Ações de promoção da pluralidade linguística em contextos escolares. 2014. 267 f. Tese (Doutorado em Letras) - Instituto de Letras, Universidade Federal do Rio Grande do Sul, Porto Alegre, 2014.

BULLIO, P. C. Referência e code-switching: traços de singularidade na linguagem de uma criança bilíngue. 2014. 655 f. Tese (Doutorado em Linguística) - Faculdade de Ciências e Letras, Universidade Estadual Paulista Julio de Mesquita Filho, Araraquara, 2014.

CALVET, L.-J. El porvenir de las lenguas. Revista El Correo de la UNESCO: Guerra y paz em el frente de las lenguas, [S. 1.], v. 53, n. 4, p. 35-36, abr. 2000.

CAVALCANTI, Marilda Couto. Estudos sobre educação bilíngue e escolarização em contextos de minorias linguísticas no Brasil. D.e.l.t.a.: Documentação de Estudos em Lingüística Teórica e Aplicada, v. 15, p. 385-417, 1999.

DÜCK, E. S. Vitalidade linguística do plautdietsch em contato com variedades standard em comunidades menonitas no Brasil. 2011. 335 f. Tese (Doutorado em Letras) - Instituto de Letras, Universidade Federal do Rio Grande do Sul, Porto Alegre, 2011.

EUCLYDES, C. Espírito santo investe na preservação da língua pomerana. Dw.com, [S.L.], n.11, p. 1-3, set. 2014. Disponível em: <http://www.dw.com/pt-br/esp\%c3\%adrito-santo-investe-napreserva\%c3\%a7\%c3\%a3o-da-1\%c3\%adngua-pomerana/a-17884813> Acesso em: 12 jan. 2019.

EWALD, L. Essa mancha ficou!: Memórias sobre práticas de letramento em cenário de imigração alemã. 2014. 110 f. Dissertação (Mestrado em Educação) - Curso de Pós-graduação em Educação, Universidade Regional de Blumenau, Blumenau, 2014.

FERRARI, L. A. A erosão linguística de italianos cultos em contato com o português brasileiro: Aspectos do sistema pronominal. 2010. 147 f. Dissertação (Mestrado em Estudos Linguísticos) Faculdade de Letras, Universidade Federal de Minas Gerais, Belo Horizonte, 2010.

FERRONI, R. As estratégias de comunicação durante a realização de tarefas feitas em colaboração por aprendizes de línguas próximas: rumo ao plurilinguismo. 2012. $301 \mathrm{f}$. Tese (Doutorado em Língua, Literatura e Cultura Italianas) - Faculdade de Filosofia, Letras e Ciências Humanas, Universidade de São Paulo, São Paulo, 2012.

GOMES, W. B. S. B. Aprendizagem e cultura: a importância de uma segunda língua para a constituição da criança. 2014. 175 f. Dissertação (Mestrado em Educação) - Centro de Ciências da Educação, Universidade Federal de Santa Catarina, Florianópolis, 2014. 
GROSJEAN, F. Life with two languages: An introduction to bilingualism. Cambridge: Harvard University Press, 1982.

GUÉRIOS, P. R. Memória, identidade e religião entre imigrantes rutenos e seus descendentes no Paraná. 2007. 299 f. Tese (Doutorado em Antropologia Social) - Programa de Pós-graduação em Antropologia Social, Universidade Federal do Rio de Janeiro, Rio de Janeiro.

HORST, A. Variação e contatos linguísticos do Vestfaliano Rio-Grandense falado no Vale do Taquari. 2014. 232 f. Dissertação (Mestrado em Letras) - Instituto de Letras, Universidade Federal do Rio Grande do Sul, Porto Alegre, 2014.

IZAWA, S. O percurso escolar dos filhos de decasséguis brasileiros retornados. 2015. $180 \mathrm{f}$. Dissertação (Mestrado) - Curso de Letras, Universidade de São Paulo, São Paulo, 2015.

IZUMI, P. T. Envelhecimento e etnicidade: o processo de aculturação dos imigrantes japoneses. 2010. 245 f. Dissertação (Mestrado em Língua, Literatura e Cultura Japonesas) - Faculdade de Filosofia, Letras e Ciências Humanas, Universidade de São Paulo, São Paulo, 2010.

KÄFER, M. L. A conscientização linguística como fundamento para uma abordagem plural no ensino de alemão-padrão em contextos de contato Português-Hunsrückisch. 2013. 156 f. Dissertação (Mestrado em Letras) - Instituto de Letras, Universidade Federal do Rio Grande do Sul, Porto Alegre, 2013.

KISS, E. V. A perda de uma língua: Os contextos sociais da perda linguística. 2013. $87 \mathrm{f}$. Dissertação (Mestrado em Letras) - Instituto de Ciências Humanas e Letras, Universidade Federal do Amazonas, Manaus, 2013.

KRIESER, D. S. "São nossas raízes, é mais uma língua nossa, a língua mãe": representações sobre a língua italiana em um contexto intercultural. 2015. 109 f. Dissertação (Mestrado em Educação) Centro de Ciências da Educação, Universidade Regional de Blumenau, Blumenau, 2015.

KUYUMJIAN, N. M. M. O ensino do francês como língua estrangeira para crianças brasileiras: Uma proposta metodológica. 2014. 140 f. Dissertação (Mestrado em Linguística Aplicada) - Instituto de Letras, Universidade de Brasília, Brasília, 2014.

LABORATÓRIO DE ESTUDOS URBANOS. Enciclopédia das línguas do Brasil. Campinas: Universidade Estadual de Campinas, 2020. Disponível em:

<https://www.labeurb.unicamp.br/elb2/pages/artigos/lerArtigo.lab?id=1> Acesso em 12 abr. 2020.

LARA, C. C. Variação fonológica, redes e práticas sociais numa comunidade bilíngue PortuguêsAlemão do Brasil meridional. 2013. 105 f. Tese (Doutorado em Letras) - Instituto de Letras, Universidade Federal do Rio Grande do Sul, Porto Alegre, 2013.

LEOPOLDINO, E. A. O dialeto trentino da Colônia Tirolesa de Piracicaba: aspectos fonéticos e lexicais. 2014. 524 f. Tese (Doutorado em Língua, Literatura e Cultura Italianas) - Faculdade de Filosofia, Letras e Ciências Humanas, Universidade de São Paulo, São Paulo, 2014.

LIMBERGER, B. K. O desempenho de bilíngues e multilíngues em tarefas de controle inibitório e compreensão auditiva. 2014. 136 f. Dissertação (Mestrado em Letras) - Faculdade de Letras, Pontifícia Universidade Católica do Rio Grande do Sul, Porto Alegre, 2014.

LORENZI, E. S. B. Políticas linguísticas para o ensino de línguas em um cenário de imigração italiana no Vale do Itajaí, SC. 2014. 102 f. Dissertação (Mestrado em Educação) - Centro de Ciências da Educação, Universidade Regional de Blumenau, Blumenau, 2014.

LUERSEN, R. W. A situação de contato plurilíngue no sul do Brasil. Visões: Revista Científica da Faculdade Salesiana Maria Auxiliadora, v. 7, p. 70-87, jul./dez. 2009. 
MAAS, M. R; FRITZEN, M. P. Relações entre currículo e dimensões linguístico-culturais em um contexto de língua minoritária. In: ANPED, 37, 2015, Florianópolis. Anais... Florianópolis: Anped, 2015. p. 1 - 17.

MAAS, S. Rais aus, die polatzai komm!: Os sentidos da língua alemã no ensino em Pomerode - SC. 2010. 95 f. Dissertação (Mestrado em Educação) - Centro de Ciências da Educação, Universidade Regional de Blumenau, Blumenau, 2010.

MARTINS, R. L. Influências interlinguísticas na fala e na escrita de crianças bilíngues falantes do português e do hunsrückisch: conscoantes oclusivas, fricativas e róticas. 2013. 369 f. Tese (Doutorado em Letras) - Faculdade de Letras, Pontifícia Universidade Católica do Rio Grande do Sul, Porto Alegre, 2013.

MEGALE, Antonieta Heyden. Bilinguismo e educação bilíngue - discutindo conceitos. Revista Virtual de Estudos da Linguagem - ReVEL, v. 3, n. 5, p. 1-13, ago. 2005.

MOTOYAMA, S. Kasato-Maru. Estud. Av., v. 25, n. 72, p. 323-326, Ago. 2011.

MOURA, S. de A. Com quantas línguas se faz um país? Concepções e práticas de ensino em uma sala de aula na educação bilíngue. 2009. 141 f. Dissertação (Mestrado em Educação) - Faculdade de Educação, Universidade de São Paulo, São Paulo, 2009.

MROCZINSKI, A. C. S. A produção e a compreensão do humor por uma criança bilíngue: um estudo de caso. 2015. 94 f. Dissertação (Mestrado em Linguística e Língua Portuguesa) - Faculdade de Ciências e Letras, Universidade Estadual Paulista Julio de Mesquita Filho, Araraquara, 2015.

MUJICA, M. M. Atitude, orientação e identidade linguística dos pomeranos residentes na comunidade de Santa Augusta - São Lourenço do Sul - RS - Brasil. 2013. 101 f. Dissertação (Mestrado em Letras) - Centro de Letras e Comunicação, Universidade Federal de Pelotas, Pelotas, 2013.

MUSEU DA IMIGRAÇÃO DO ESTADO DE SÃO PAULO. 2020. Disponível em: $<$ http://www.museudaimigracao.org.br/> Acesso em 22 abr. 2020.

MUSEU ETNOGRÁFICO DA COLÔNIA MACIEL. Imigração italiana no Rio Grande do Sul. 2020. Disponível em: <https://wp.ufpel.edu.br/museumaciel/imigracao-italiana-no-rio-grande-do-sul/> Acesso em 22 abr. 2020.

NOBRE, W. C. A. Introdução à história das línguas gerais no Brasil: Processos distintos de formação no Período Colonial. 2011. 233 f. Dissertação (Mestrado em Letras) - Instituto de Letras, Universidade Federal da Bahia, Salvador, 2011.

PEREIRA, L. N. A relação do bilinguismo com capacidades cognitivas: memória de trabalho, atenção, inibição e processamento de discurso. 2012. 129 f. Dissertação (Mestrado em Letras) Faculdade de Letras, Pontifícia Universidade Católica do Rio Grande do Sul, Porto Alegre, 2012.

PINHEIRO, L. S. Processos de territorialização de variedades dialetais do italiano como línguas de imigração no nordeste do Rio Grande do Sul. 2014. 165 f. Tese (Doutorado em Letras) Instituto de Letras, Universidade Federal do Rio Grande do Sul, Porto Alegre, 2014.

QUADROS, J. E. A opção pela Educação Infantil bilíngue por famílias de Belo Horizonte: Perfil social e motivações. 2013. 130 f. Dissertação (Mestrado em Educação) - Faculdade de Educação, Universidade Federal de Minas Gerais, Belo Horizonte, 2013.

ROSA, E. K. Fatores de manutenção e regressão da língua e cultura alemãs no município de Missal - Paraná. 2011. 194 f. Dissertação (Mestrado em Letras) - Centro de Educação, Comunicação e Artes, Universidade Estadual do Oeste do Paraná, Cascavel, 2011. 
SAKAGUCHI, N. F. Alfabetizar letrando em português como língua estrangeira: as estórias não contadas por um grupo de crianças coreanas. 2010. 161 f. Dissertação (Mestrado em Linguística Aplicada) - Instituto de Estudos da Linguagem, Universidade Estadual de Campinas, Campinas, 2010.

SEYFERTH, G. A assimilação dos imigrantes como questão nacional. Mana, v. 3, n. 1, p. 95 131, abr. 1997.

SILLER, R. R. Infância, Educação Infantil, Migrações. 2011. 261 f. Tese (Doutorado em Educação) - Faculdade de Educação, Universidade Estadual de Campinas, Campinas, 2011.

SILVA, A. G. da. Recortes interculturais: Percepções de uma comunidade bilíngue acerca das línguas e culturas norte-americana e brasileira. 2010. 144 f. Dissertação (Mestrado em Letras e Linguística) - Faculdade de Letras, Universidade Federal de Goiás, Goiânia, 2010.

SILVA, E. D. Qual bilinguismo temos e queremos para os estudantes surdos na educação básica? Revista FORPROLL, v. 1, n. 1, 2017, p. 60-72. Disponível em:

<http://forproll.com/wp-content/uploads/2017/02/05-Eduardo-Dias-da-Silva_ret.pdf> Acesso em 22 abr. 2020.

SILVA, F. B. da. Produção oral e escrita dos róticos em Arroio do Padre (RS): avaliando a relação português/pomerano com base na Fonologia Gestual. 2015. 246 f. Dissertação (Mestrado em Letras) Centro de Letras e Comunicação, Universidade Federal de Pelotas, Pelotas, 2015.

SIMIONATO, M. M. O processo de alfabetização e a diáspora da língua materna na escola: Um estudo em contexto de imigração ucraniana no sul do Brasil. 2012. $290 \mathrm{f}$. Tese (Doutorado em Educação) - Centro de Ciências da Educação, Universidade Federal de Santa Catarina, Florianópolis, 2012.

SPIESS, V. B. Discursos sobre ensino bilíngue em contexto intercultural: as vozes das famílias. 2014. 139 f. Dissertação (Mestrado em Educação) - Centro de Ciências da Educação, Universidade Regional de Blumenau, Blumenau, 2014.

SPINASSÉ, K. P. Educação Bilíngüe em contextos multilíngües. In: CELSUL, 8. 2008, Porto Alegre. Anais... Porto Alegre: Celsul, 2008. p. 1-8.

TAKANO, Y. Esboço do atlas do falar dos nipo-brasileiros do Distrito Federal: aspecto semântico-lexical. 2013. 362 f. Tese (Doutorado em Linguística) - Faculdade de Filosofia, Letras e Ciências Humanas, Universidade de São Paulo, São Paulo, 2013.

TRENTO, A. Do outro lado do Atlântico: um século de imigração italiana no Brasil. São Paulo: Nobel, 1988.

VIEIRA, M. M. Para um estudo das influências fonológicas do italiano no português falado na cidade de São Paulo. 2010. 73 f. Dissertação (Mestrado em Língua, Literatura e Cultura Italiana) Faculdade de Filosofia, Letras e Ciências Humanas, Universidade de São Paulo, São Paulo, 2010.

WACHOWICZ, R. C. História do Paraná. Curitiba: Ed. dos Professores, 1967.

WEI, Li. Dimensions of Bilingualism. In: WEI, Li. The Bilingualism Reader. 13. ed. London/ New York: Routledge, 2000.

YIN, B. M. Imigração chinesa em São Paulo e seu português falado: Interlíngua e marcadores discursivos. 2013. 106 f. Dissertação (Mestrado em Filologia e Língua Portuguesa) - Faculdade de Filosofia, Letras e Ciências Humanas, Universidade de São Paulo, São Paulo, 2013. 